\title{
AN INTERESTING CONCRETION
}

\section{A. J. HRUSKA, Gerald, Saskatchewan SOA 1B0}

The usual description of a concretion as having concentric internal structure does not appear to fit the concretion which is the subject of this note. I picked up this specimen in the field several years ago because of its very interesting configuration, which can be seen in the accompanying photo.

The rock is approximately $9 \mathrm{~cm}$ high, $15 \mathrm{~cm}$ long, and $6.5 \mathrm{~cm}$ thick. It is roughly trifacial and the bottom is covered with a heavy patina of lime. The material is a dark grey sediment and is usually referred to as greywacke or ironstone on the prairies. A similar illustration can be found in Concretions and some other Sedimentary Structures.
The chief interest of this concre is the design which appears to be cised or eroded into the rock at a iform depth, except where mar " $X$ ". Though the outside design is cular the inside "hairpin" design I cast doubt on its being a concre since this is a design inside a des Further, the two different angle incision are very interesting. The side ring which is quite uniform is cised at about $50^{\circ}$ to the plane of rock, whereas the hairpin incisio perpendicular to the same pla Both incisions are to the same de except where indicated, and about $3 \mathrm{~mm}$ wide.

In my opinion the difference angles of incision or erosion

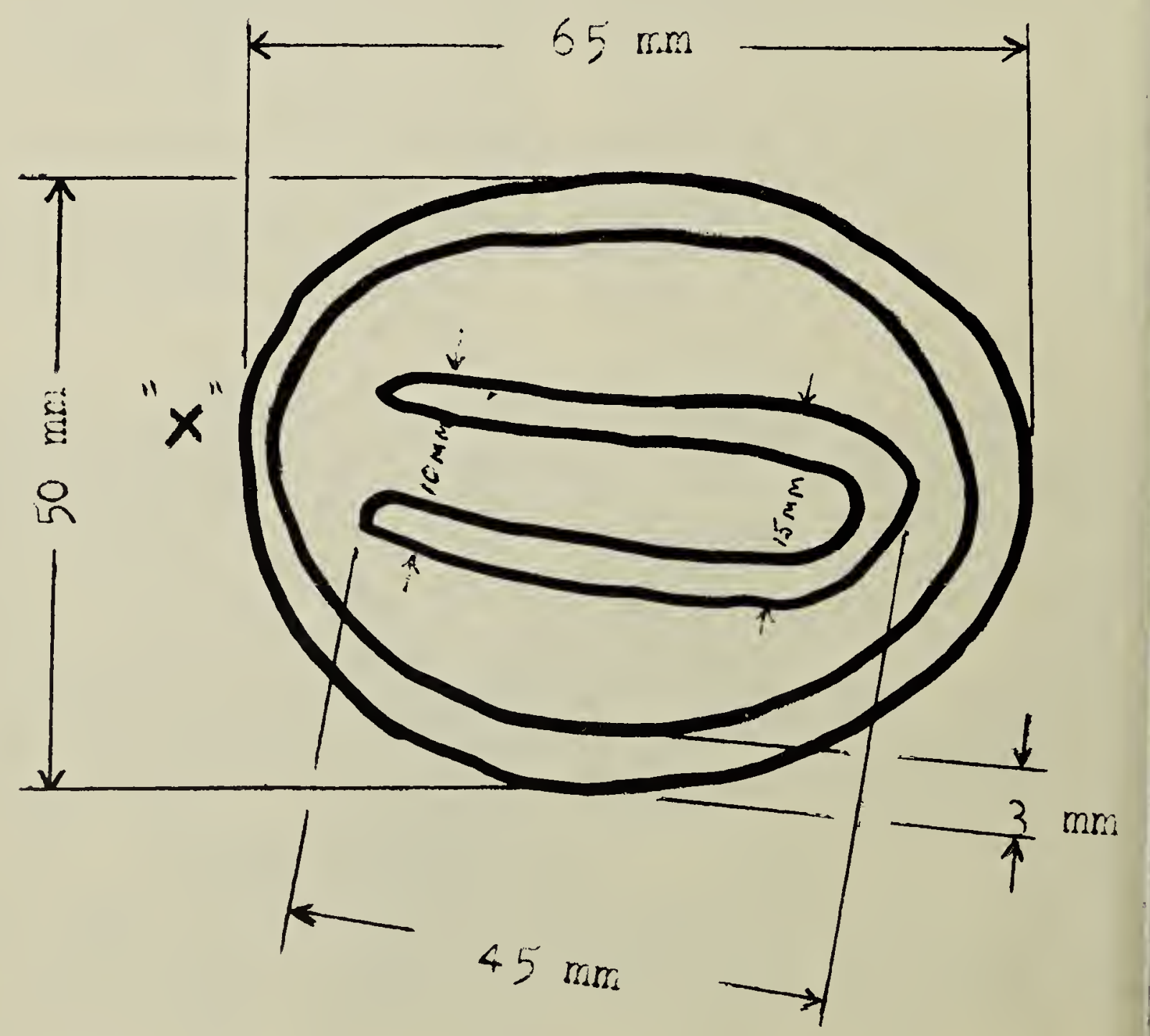


